\title{
Nondestructive Analysis of Sweet Corn Maturity Using NMR
}

\author{
R. Roger Ruan ${ }^{1}$ and Paul L. Chen ${ }^{2}$ \\ Department of Biosystems and Agricultural Engineering, University of \\ Minnesota, 1390 Eckles Avenue, St. Paul, MN 55108
}

\author{
Simon Almaer ${ }^{3}$ \\ Pillsbury Technology Center, 330 University Avenue SE, Minneapolis, \\ MN 55414
}

\section{Additional index words. nuclear magnetic resonance, relaxation, heat unit, AIS, moisture content, Zea mays}

\begin{abstract}
This paper describes the relationship between the maturity stages and nuclear magnetic resonance (NMR) characteristics of sweet corn (Zea mays L.). The NMR parameter $T_{2}$, which is the spin-spin relaxation time constant, and two conventional maturity parameters, moisture content and alcohol insoluble solids (AIS), of sweet corn samples during maturation, were determined and correlated with reference maturity indices, namely, heat units and sensory maturity scores. The relationships between $T_{2}$ and the heat unit and sensory maturity score of the samples were linear, suggesting that $T_{2}$ can be used to establish mathematical models for the prediction of sweet corn maturity to determine harvest time. The major advantages of using NMR are the nondestructive nature, the speed, and the simplicity of the method.
\end{abstract}

There are many reasons why crops should be harvested at optimal maturity for their specific end uses. In general, fruits used for fresh consumption should be more mature at harvest than those used for processing so that their taste, flavor, aroma, color, and texture are maximized. Other factors affecting the decision as to when to harvest fruits include target storage duration, storage and transportation facilities, and type of processing. Immature sweet corn does not have the best sensory quality; when overmature, it is not as sweet and has an unpleasant texture because of high levels of water-soluble polysaccharides. An accurate determination of sweet corn maturity for harvest can ensure best possible crop yield and quality. A more worrisome problem is that the ears can remain in their prime condition for a few hours to several days depending on the field temperature. This makes maturity determination a vital step in the growing, harvesting, and processing of sweet corn.

The maturity of a crop is generally determined by chemical and physical means. The maturity of sweet corn can be determined by measuring the moisture content (Williams et al., 1950), soluble solids (Scott et al., 1945),

\footnotetext{
Received for publication 4 Dec. 1997. Accepted for publication 13 Oct. 1998. Published as paper No 980920 of the Scientific Journal Series of the Minnesota Agricultural Experiment Station. Mention of trade name is solely to provide specific information and does not constitute its endorsement over similar products not mentioned. The cost of publishing this paper was defrayed in part by the payment of page charges. Under postal regulations, this paper therefore must be hereby marked advertisement solely to indicate this fact.

${ }^{1}$ Associate Professor.

${ }^{2}$ Research Associate.

${ }^{3}$ Scientist.
}

found that changes in both solid phase (e.g., starch) and liquid phase (e.g., water, low molecular weight sugars, mobile lipids, etc.) were observed by ${ }^{1} \mathrm{H}$ NMR on intact banana fruits during ripening. They attributed the increase in liquid phase and decrease in solid phase to the conversion of starch to sugars during ripening. Chen et al. (1993) reported that the ratio of the oil to water resonance peaks of the onedimensional NMR spectrum, and the spinlattice relaxation time $\left(\mathrm{T}_{1}\right)$ and spin-spin relaxation time $\left(\mathrm{T}_{2}\right)$ of water in avocado fruit were correlated with maturity of the fruit. Changes in chemical composition and structure of plant tissues during growth and development may be reflected in changes in the properties of water in the tissue. Since NMR is also a tool for probing physical properties of water in biological materials, an NMR sensor might be developed to determine the development state (i.e., maturity) of plant tissue through the measurable properties of water. Spin-spin relaxation time constant $T_{2}$ is an important NMR parameter that can be related to the physical properties of water molecules in biological materials. This constant often changes as the histological structure and chemical composition change during tissue maturation. Unlike NIR, NMR does not require a complicated calibration procedure and its operation is straightforward.

In the present study, we compared the $\mathrm{T}_{2}$ of a sweet corn cultivar during maturation with moisture content, AIS, HU, and sensory maturity scores in order to explore the possibility of using NMR for nondestructive prediction of harvest date.

\section{Materials and Methods}

indicators. Linear relationships exist between moisture content, AIS, and HU. However, all the methods mentioned above involve cutting and other extensive preparation work, and are therefore destructive and often time-consuming.

Several techniques for nondestructive evaluation of quality of stored fruits and vegetables were reviewed by Dull (1986) and Abbott et al. (1997). Some of these techniques are actually used for maturity and ripeness determination. For example, near infrared (NIR) spectroscopy has been used for nondestructive determination of chemical parameters such as protein, soluble solids, acidity, dry matter, pectin, and starch in fruits, vegetables, grains, and other crops (Lovasz et al., 1993; Noaman and Taylor, 1990; Shiina et al., 1992). Most of these chemical parameters are related to the physiological stages or maturity of crops, and NIR has great potential as an alternative nondestructive instrumental tool for determination of crop development stages and maturity (Czuchajowska and Pomeranz, 1989; Lovasz et al., 1993). Nuclear magnetic resonance spectroscopy is another nondestructive technique, and is receiving increasing attention from food scientists and biologists. An excellent technique for chemical analysis, NMR has been used to evaluate the quality and determine chemical composition of fruits and vegetables (Bellon et al., 1992; Chen et al., 1989; Cho et al., 1993). Ni and Eads (1993)
A sweet corn supersweet hybrid (Jubilee Super Sweet Code 60) was used in this study. All plants were grown in the same field and under the same growing conditions, and samples were taken at various stages of maturity. Values for HU were calculated by accumulating the daily effective temperature, which was the difference between the base temperature $\left(4.4^{\circ} \mathrm{C}\right)$ and the daily average temperature. The maturity of the samples was scored by a five-person expert panel, based on a ninepoint scale, where 1 was extremely immature and 9 was extremely overmature. Based on previous research, a score of 3 was regarded as the best maturity for canning. All collected samples were grouped according to maturity, and 10 cobs per group were used for the tests. The moisture contents of the samples were determined using a standard oven drying method and the AIS contents by the NIR method described by Nielsen (1994). The $T_{2}$ was measured with a 4.7 Tesla SISCO NMR Spectrometer (Varian, Palo Alto, Calif.), using a CPMG (Carr-Purcell-Meiboom-Gill) pulse sequence for data acquisition. The power width and interpulse delay time for the $90^{\circ}$ pulse were $100 \mu \mathrm{s}$ and $7.5 \mathrm{~s}$, respectively. All analyses were done within 4 to $6 \mathrm{~h}$ after the samples were collected from the field. Each test sample was a composite of excised kernels from the 10 cobs collected on the same day. 

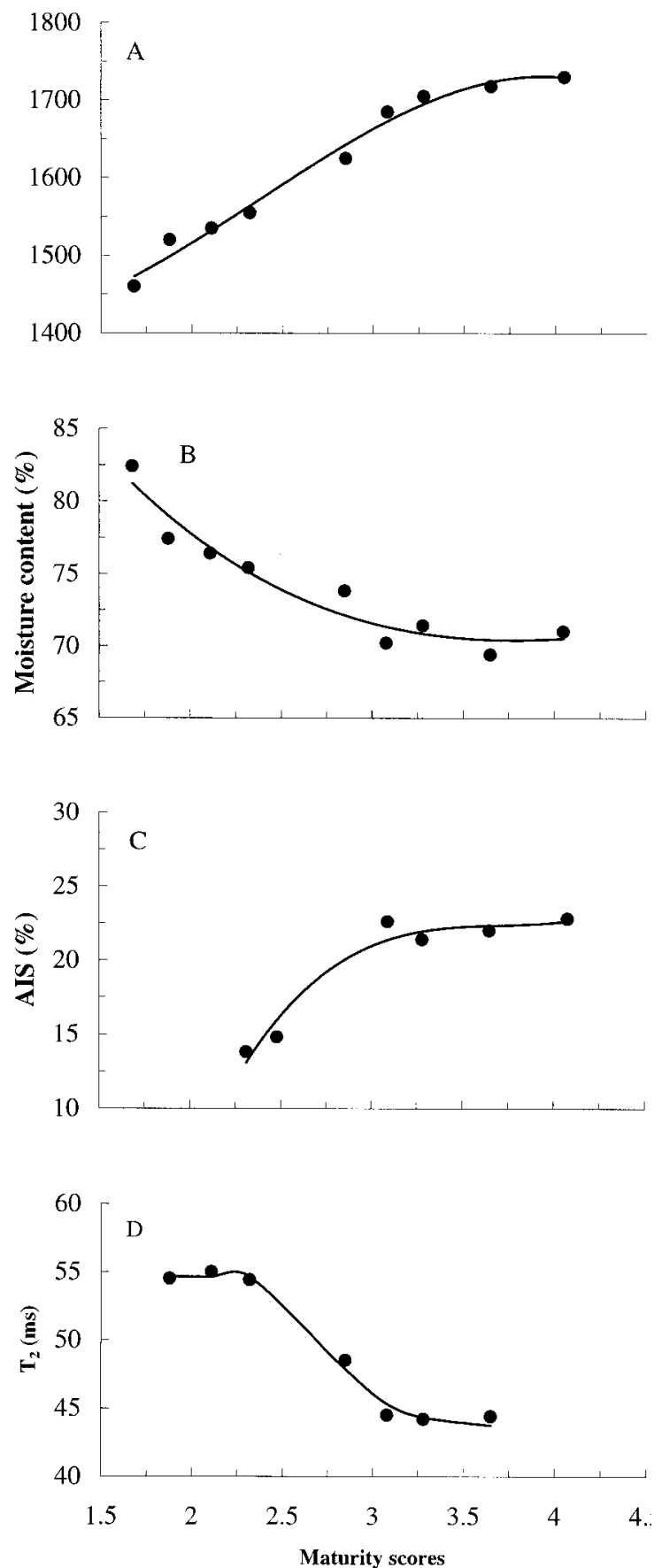

Fig. 1. Relationships between sensory maturity scores $(1=$ extremely immature, and $9=$ extremely overmature) in sweet corn and (A) heat units, (B) moisture content, (C) alcohol insoluble solids (AIS), and (D) spin-spin relaxation time $\left(\mathrm{T}_{2}\right)$.
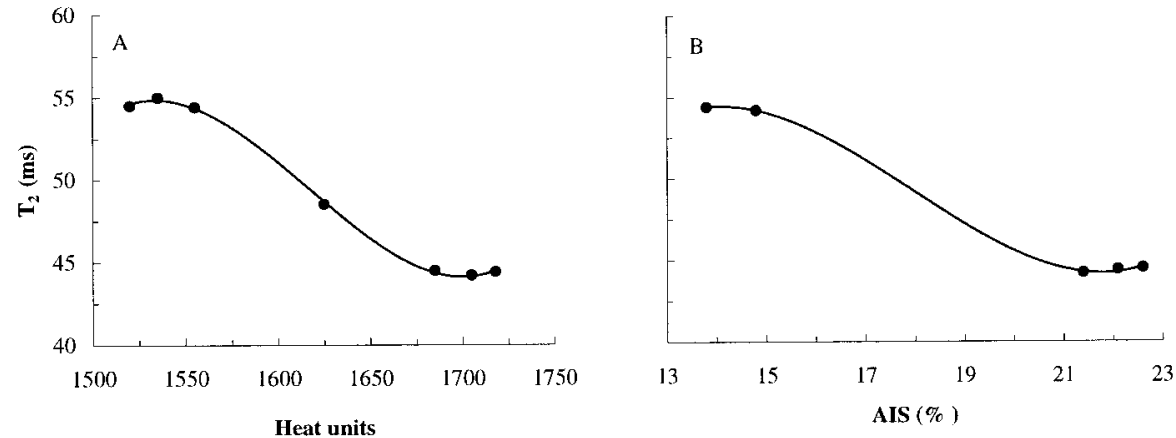

Two replicates were used for each measurement, and the average is presented. Data were analyzed using Kaleidagraph 3.0 (Synergy Software, Reading, Pa.).

\section{Results and Discussion}

We found that HUs correlated very well with the sensory maturity scores (Fig. 1A). However, because the HUs required for sweet corn to develop vary with several factors, including cultivar, soil, climatic conditions, and plant nutrition, HUs can only be used as a guide. Furthermore, since obtaining HU data involves much work, more critical and simple measurements are needed to ensure reliable prediction of maturity.

Moisture content of the sweet corn kernels decreased while AIS increased as the corn kernels matured (Fig. $1 \mathrm{~B}$ and C), in agreement with published data. The spin-spin relaxation time constant $\mathrm{T}_{2}$ decreased with maturity score, indicating a decrease in mobility of protons in the samples (Fig. 1D). This can be attributed to the decrease in moisture content and the increase in water soluble solids and viscosity. Thus $\mathrm{T}_{2}$ decreased with HUs (Fig. 2A) and AIS (Fig. 2B), and increased with moisture content (Fig. 2C). The relationship between $\mathrm{T}_{2}$ and maturity $(M)$ shown in Fig. 1D can be described using a sigmoidal model (Weibull model):

$$
T_{2}=a-b \exp ^{-c M^{d}}
$$

where $a=59.65, b=11.12, c=514368.90$, and $d=-13.23$ are constants. The value of $r^{2}$ was 0.989 with a standard error of prediction of 0.592 .

One must be cautious when using this model for prediction of harvest maturity because of the decreased sensitivity at both ends of the continuum, and more research is needed to test this model. Variables that may affect the predictability of the model should also be considered. Such variables may include growing conditions, cultivar, and agronomic activities.

Note that in this study, the $\mathrm{T}_{2}$ values detected by the NMR instrument were in the range of 20 to $25 \mathrm{~ms}$. In general, $\mathrm{T}_{2}$ values in this range represent relatively mobile water in the system. Some techniques using low field NMR are capable of detecting much shorter $\mathrm{T}_{2}$ values representing "bound" or less mobile

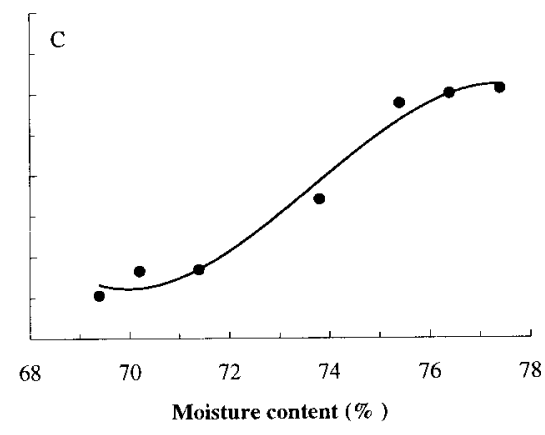

Fig. 2. Relationships between spin-spin relaxation time, $\mathrm{T}_{2}$, and (A) heat units, (B) alcohol insoluble solids, and (C) moisture content (AIS). 
water (Ruan et al., 1996; Ruan and Chen, 1998). Our experience in low field NMR studies of biological materials has indicated that $\mathrm{T}_{2}$ values in different time-domains reflect differences in chemical composition, structure, and physiological states of the materials. By analyzing the relationships between each of the proton components of different relaxation time domains and the chemical properties and maturity of sweet corn, more reliable and accurate prediction models may be established.

\section{Literature Cited}

Abbott, J.A., R. Lu, B.L. Upchurch, and R.L. Stroshine. 1997. Nondestructive evaluation of fruits and vegetables. Hort. Rev. 20:1-120.

Arthey, V.D. 1978. The production, processing and quality of sweet corn. Campden Food Preserv. Res. Assoc. Tech. Bul. No. 39.

Bellon, V., S.I. Cho, G.W. Krutz, and A. Dvaenel. 1992. Ripenesssensordevelopmentbasedonnuclear magnetic resonance. Food Control 2:45-48.

Chen, P., M.J. McCarthy, and R. Kauten. 1989. NMR for internal quality evaluation of fruits and vegetables. Trans. ASAE 32:1747-1753.

Chen, P., M.J. McCarthy, R. Kauten, Y. Sarig, and S. Han. 1993. Maturity evaluation of avocados by NMR methods. J. Agr. Eng. Res. 55:177-187.

Cho, S.I., R.L. Stroshine, I.C. Baianu, and G.W Krutz. 1993. Nondestructive sugar measurement of intact fruit using spin-spin relaxation times $\left(\mathrm{T}_{2}\right)$ measurements by pulsed ${ }^{1} \mathrm{H}$ magnetic resonance. Trans. ASAE 36:1217-1221.

Crawford, T.M. and W.A. Gould. 1957. Application of specific gravity techniques for the evaluation of quality of sweet corn. Food Technol. 11:624 627.

Culpepper, C.W. and C.A. Magoon. 1972. A study of the factors determining quality in sweet corn. J. Agr. Res. 34:413-433.

Czuchajowska,Z. and Y. Pomeranz. 1989. Changes in maturing wheat as determined by near-infrared reflectance spectroscopy. Cereal Chem. 66:432-435.

Darbyshire, B., W.A. Muirhead, and R.J. Henry. 1978. Water-soluble polysaccharides determination as a technique for evaluation of sweet corn maturity. Aust. J. Agr. Res. 29:517-522.

Desai, B.B. and D.K. Salunkhe. 1991. Fruits and vegetables, p. 301-412. In: D.K. Salunkhe and S.S. Deshpande (eds.). Foods of plant origin: Production, technology, and human nutrition. Van Nostrand Reinhold, New York.

Dull, G.G. 1986. Nondestructive evaluation of quality of stored fruits and vegetables. Food Technol. 40:106-110.

Henry, C.H., E.B. Wilcox, L.H. Pollard, D.K Salunkhe, and F.E. Lindqyust. 1956. Evaluation of certain methods to determine maturity in relation to yield and quality of yellow sweet corn grown for processing. Food Technol. 10:374380 .

Lovasz, T., P. Meresz, A. Salgo, and P. Sass. 1993 Physical methods for detection of physiological changes in apples during storage. Acta. Hort. 343:59-60.
Ni, Q.X. and T.M. Eads. 1993. Analysis by proton NMR of changes in liquid-phase and solidphase components during ripening of banana. J. Agr. Food. Chem. 41:1035-1040.

Nielson, S.S. 1994. Introduction to the chemical analysis of foods. Jones and Bartlett, Boston.

Noaman, M.M. and G.A. Taylor. 1990. Vegetative protein and its relation to grain protein in high and low grain protein winter wheats. Euphytica $48: 1-8$.

Ruan, R. and P. Chen. 1998. Water in foods and biological materials-A nuclear magnetic resonance approach. Technomic Publ., Lancaster, $\mathrm{Pa}$.

Ruan, R., C. Zou, C. Wadhawan, B. Martinez, P. Chen, and P. Addis. 1996. Studies of water mobility and shelf life quality of precooked wild rice using pulsed NMR. J. Food Process. Preserv. 21:91-104.

Scott, G.D. R.O. Belkengren, and E.C. Ritchell. 1945. Maturity of raw sweet corn determined by refractometer. Food Ind. 17:1030-1032.

Shiina, T., T. Ijiri, I. Matsuda, T. Sato, S. Kawano, N. Ohoshiro, D.P. Bartholomew, and K.G. Rohrbach. 1992. Determination of brix value and acidity in pineapple fruits by near infrared spectroscopy. Acta Hort. 334:261-272.

Tung, M.A., M.R. Gardland, A.R. Maurer, and T.K. Watson. 1974. Rheological and sensory evaluation of sweet corn maturity. Can. Inst. Food Sci. Technol. J. 7:136-142.

Williams, K.T., E.A. McComb, and B.L. Washauer. 1950. Quick test for sweet corn quality. Food Ind. 22:75-77. 